\title{
Electromechanical Battery EMB Mass Minimization taking into Account its Electrical Machines Rotor Energy
}

\author{
Andrejs Podgornovs (Researcher, Riga Technical University - RTU), \\ Antons Sipovichs (Doctoral Student, RTU)
}

\begin{abstract}
In this paper the electromechanical battery (EMB) with synchronous machine is described. Theoretically, if electrical machines rotor stored energy is known, it is possible to reduce the flywheel mass of electromechanical battery. For example, the efficiency of energy recovery (kilowatt-hours out versus kilowatthours in) in nowadays appliances exceeds $95 \%$ which is considerably better than of any electrochemical battery, such as lead-acid battery. For the rotor stored energy amount calculation, it is necessary to find all geometrical dimensions of the electrical machine. To achieve this goal the iterative calculation method was used. Electromechanical battery mass was analyzed as a discharge process rotation speed function. Taking into account the rotor stored energy, we can increase the minimum rotation speed thus reducing the electrical machine mass and increasing the flywheel mass, which provides EMB cost reduction. Additionally, the possibilities of using numerical approximation calculations of magnetization curves are discussed. Each iteration of numerical application necessary for the method for rapid calculation is essential when calculating the field problems. Nowadays there are a lot of computer added design programs for electromagnetic field calculation in different types of applications, electrical machines and apparatus. For the electromagnetic field calculation process some more commonly used magnetization curve approximation methods are described, and the machine calculation time is tested for different numbers of calculations.
\end{abstract}

Keywords - Flywheels; Minimization methods; Approximation algorithms; Numerical simulation; Design optimization.

\section{INTRODUCTION}

Energy storage nowadays is important for the national economy; using energy storage applications possible to enlarge power system stability improve customer power quality protecting customers from various types of fluctuations, which adversely affects the production processes. Energy can be accumulated in different ways, each of them has advantages and disadvantages, and it is possible to store energy in the rotating mass. This method has a long history, but from the end of the 20th century, when appeared new technological possibilities to increase the specific energy per mass unit, it takes a new life, and occupies a significant place among energy storage applications.

\section{ELECTROMECHANICAL BATTERY}

Electromechanical battery stores energy in the kinetic form, the storage application battery is a rotating disk - flywheel. There are various flywheel designs, as well as a wide range of materials. The charging of the flywheel with energy and the discharging process require the use of electrical machine; in the charging process this machine is working in motor mode, and in the discharge process it serves as a generator. The quantity of the stored energy can be solved by

$$
W=J \frac{\omega^{2}}{2},
$$

where $J$ is the flywheel moment of inertia, $\mathrm{kg} \cdot \mathrm{m}^{2}$, and $\omega$ is angular velocity, rad/s. The equation shows that the accumulated quantity of energy can be increased in two ways: by increasing the rotating mass $J$ or speed $\omega$. It is more reasonable to increase the speed because it is included in the formula in power 2 .

\section{ROTOR ENERGY}

The main component of different types of electromechanical battery EMB is electrical machine. The common equation of battery mass is

$$
m_{E M B}=m_{S P}+m_{M A},
$$

where $m_{E M B}$ is mass of EMB, $\mathrm{kg}, m_{S P}$ is flywheel mass, $\mathrm{kg}$, and $m_{M A}$ is mass of electrical machine, $\mathrm{kg}$ [2]. Flywheel mass equation is stated as

$$
m_{S P}=\frac{4 W}{\eta_{i z l}\left(R_{S P} \omega_{1}\right)^{2}\left(1-\omega_{2^{*}}^{2}\right)},
$$

where $W$ stands for quantity of energy, $\mathrm{J}$, that can be taken (or loaded) from the spinning disk, if the relative minimal rotation speed at the end of the discharge process is $\omega_{2^{*},}, \eta_{i z l}$ is efficiency coefficient of discharge process, $R_{S P}$ is flywheel radius, m, and $\omega_{1}$ is maximal angular velocity of EMB,

$$
\omega_{2^{*}}=\omega_{2} / \omega_{1}=\left(\omega_{1}-\Delta \omega\right) / \omega_{1}[1] .
$$

The mass of electrical machine is calculated using classical design equations, and as an example a synchronous machine with electromagnetic excitation is described. This type of electrical machines can provide voltage regulation in the discharge mode, when angular velocity drops down, by increasing excitation current the output voltage can be close to nominal value. To find the mass of electrical machine it is necessary to find the internal stator diameter $D 1$ and stator length $l_{1}$, the main relationship between the dimensions of the machine and electrical and magnetic parameters can be expressed through Arnolds machinery constant 
$2014 / 7$

$$
C_{A}=\frac{D_{1}^{2} l_{1} n}{P_{e m}}=\frac{1}{\pi^{2} \alpha_{\delta} B_{\delta} A_{1}},
$$

where $n$ is rotation speed, $\min ^{-1}, \alpha_{\delta}$ is relative pole which shows the relationship

$$
\frac{B_{\delta_{-} \text {average }}}{B_{\delta_{-} \max \text { imal }}} .
$$

In turn, $B_{\delta}$ is the maximum air gap flux density, $A_{1}$ is electric loading of machine and $P_{e m}$ is electromagnetic power of the machine.

The equations of mass of the electrical machine equations are as follows:

$$
\begin{gathered}
D_{1}^{2} l_{1}=\frac{2 P_{i z l} k_{E}}{k_{f} \omega_{1} \omega_{2^{*}} k_{t i n} \alpha_{\delta} B_{\delta} A_{1} \pi \cos \varphi} \text { and } \\
m_{M A}=\frac{\pi k_{D}^{2}}{4}\left(D_{1}^{2} l_{1}\right) \gamma_{t e r},
\end{gathered}
$$

where $k_{f}$ is field form factor, which shows the ratio between real EMF and its average value, $P_{i z l}$ is discharge power of EMB, $k_{t i n}$ is stator winding factor, $\cos \varphi$ is power factor, $\gamma_{t e r}$ is the density of materials (electro-technical steel and winding cooper) of the electrical machine and $k_{D}$ is the outer and internal diameter ratio of the electrical machine [4].

Kinetic energy stored in the rotor $W_{\text {rot }}$ of the electrical machine depends on the power of discharge process, on process duration and quantity of energy. Determination of $W_{\text {rot }}$ requires the calculation of the geometrical dimensions of the electrical machine, going through accurate and standard design calculation process.

In Fig. 1 flywheel, electrical machine and EMB mass curves, which are $\omega_{2} *$ relative angular velocity functions, are displayed. These graphs were created from (1), (2) and (3) without taking into account kinetic energy stored in the rotor of the electrical machine.

It is clear, that if we want to find optimal $\omega_{2} *$ which provides minimum mass of EMB and reduces this mass taking into account $W_{\text {rot }}$, we should recalculate the machine for different $\omega_{2} *$ values in $(0 ; 1)$ diapason; for each point we should determine rotor dimensions and $W_{\text {rot }}$ for $\omega_{2 *}$, then the flywheel mass can be calculated. The main problem of the design of electrical machines is the fact that equation (3) does not give ratio $\lambda=l_{1} / D_{1}$.

Electrical machine stator may be of different constructions, but for calculation we take half opened trapezoidal stator slot, two pole $(2 \mathrm{p}=2)$ salient pole rotor with excitation winding, regular air gap; and also $\alpha_{\delta}, B_{\delta}, A_{1}$ and $\omega_{1}$ are taken as constants. Mass calculation requires to take electro-technical and cooper density, nominal voltage, stator tooth flux density, rotor and stator yoke flux density, phase parallel wire number, EMB stored energy, discharge frequency $\left(t_{c i k l}=30 \mathrm{sec}\right)$, which is necessary for maximum current density calculation, but for relatively short $t_{\text {cikl }}$ it can be calculated as (6)

$$
j_{\text {tin }} \approx j_{i \lg s t} / \sqrt{t_{*}},
$$

where $j_{\text {tin }}$ is maximum stator winding current density, $j_{i l g s t}$ is long period permissible current density and $t_{i z l}$ is discharge period duration [2].

To calculate all design combinations and variants of electrical machine the calculation program was created. Its logical scheme is given in Fig. 2.

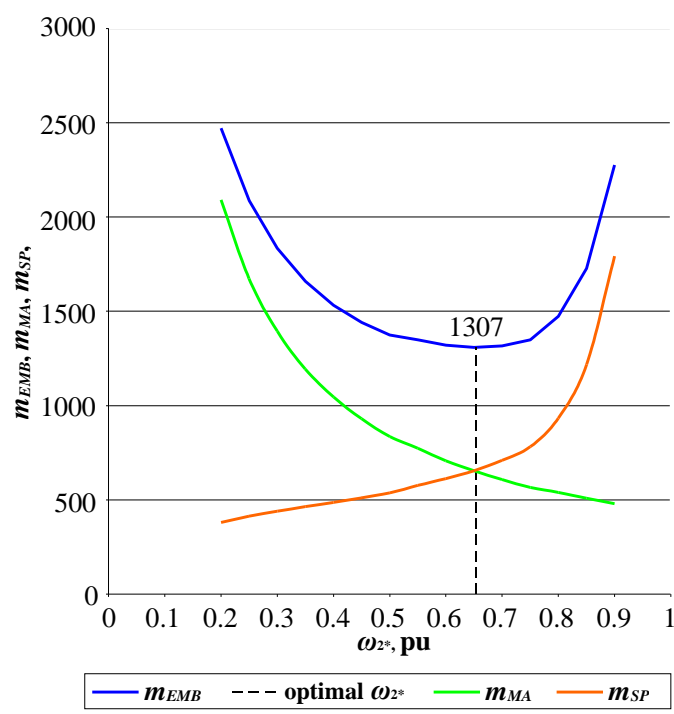

Fig. 1. EMB, electrical machine and flywheel mass curves without rotor kinetic energy, discharge process duration 5 seconds.

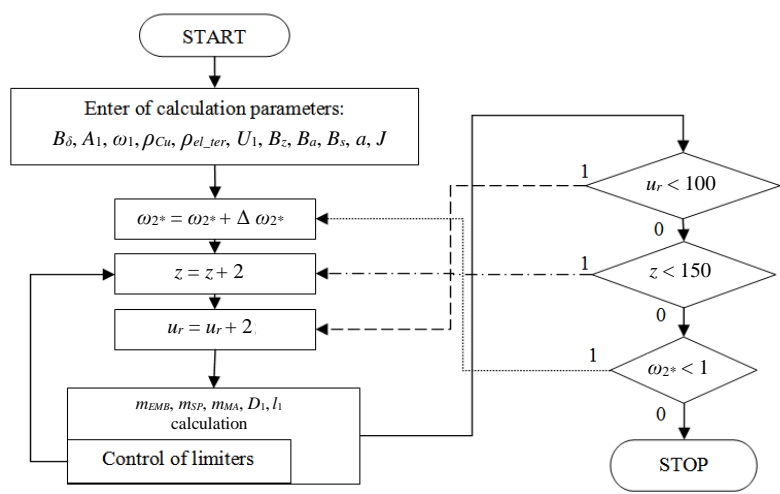

Fig. 2. Calculation program logical scheme.

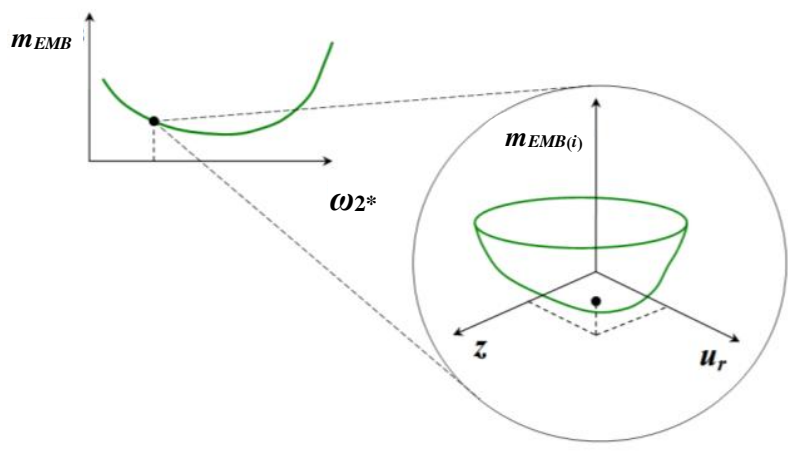

Fig. 3. $m_{E M B}$ curve and $i$-number calculation step with $m_{E M B}(i)$ curve.

For $\omega_{2} *$ diapason a step value $\omega_{2} *=0.025$ is chosen. At each step electrical machine is recalculated, with minimum mass parameters. To achieve this goal iterative calculation method is used. It is necessary to calculate machine parameters for 
different stator slot number $z$ (which rises up to 100 , with step $\Delta z=6$ ) and $u_{r}$ which is slot effective wire number (up to 150 , with step $\Delta u_{r}=2$ ), for each combination $u_{r}$ and $z$ we calculate $m_{E M B}, m_{S P}, m_{M A}$, described calculation process graphical interpretation in Fig. 3.

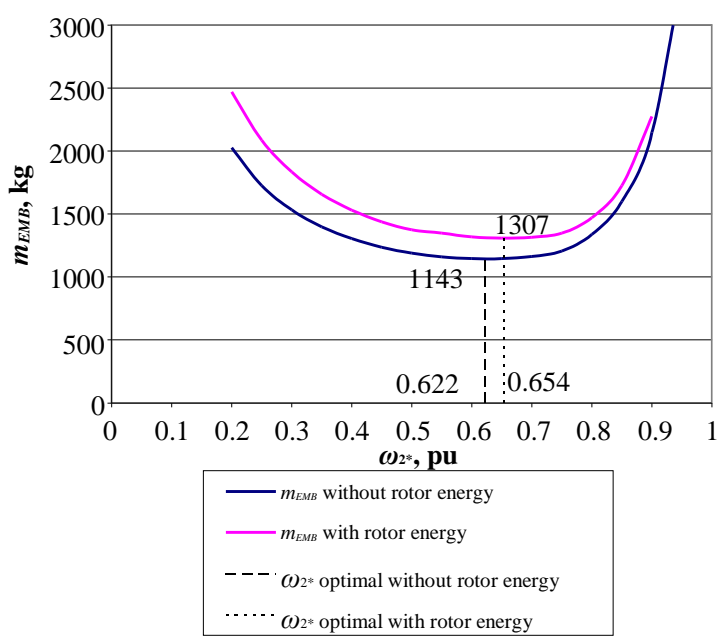

Fig. 4. $m_{E M B}$ curves with and without rotor energy, discharge period $5 \mathrm{~s}$.

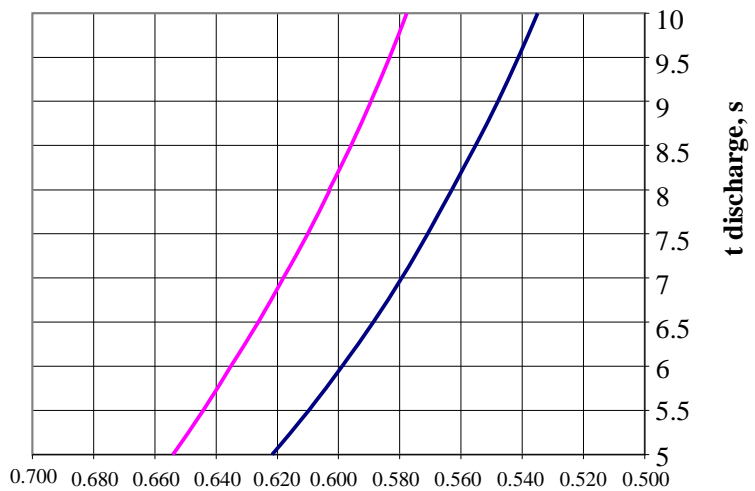
$\omega_{2^{*}}, \mathbf{r . v}$.

$$
\text { - Without rotor energy — With rotor energy }
$$

Fig. 5. $m_{E M B} \omega_{2^{*}}$ optimal curves with and without rotor energy with different discharge time.

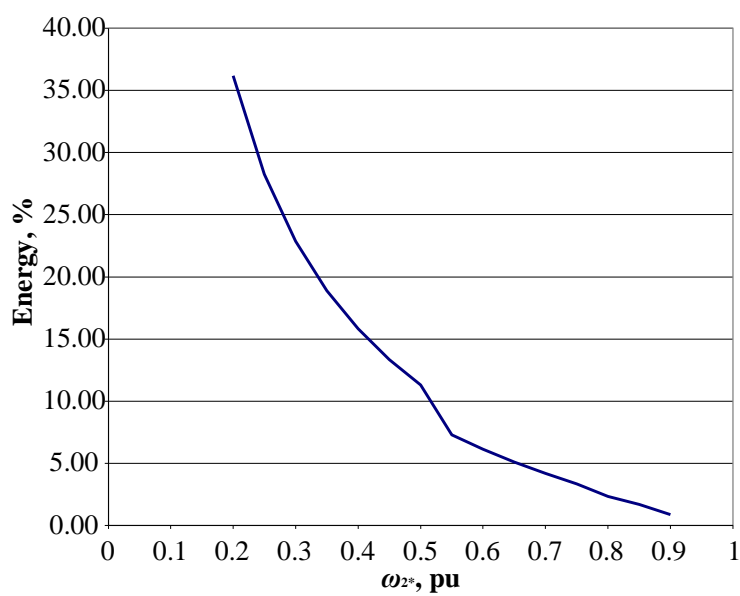

Fig. 6. $m_{E M B}$ relative rotor energy as function of $\omega_{2^{*}}$ optimal.
There is a group of limiting factors: stator and rotor yoke flux density, stator tooth flow density, $l_{1}, D_{1}$ and their ratio $\lambda$. Taking into account the allowable calculation result values it is possible to stop $i$-number calculation, and to start $i+1$ calculation, and in this way to reduce the calculation time [3]. Then it is clear that the accurate calculation of electrical machine increases EMB application mass (Fig. 4.).

Simple calculation equations (3), (4), (5) calculate optimal $\omega_{2} *$ not equal to the optimal $\omega_{2} *$ calculated through the accurate design process. The positive result of taking into account the kinetic energy of the rotor of the electrical machine is that $\omega_{2 *}$ has increased, it means that at the end of the discharge process the excitation system designed for minimum angular velocity is reduced.

Using accurate calculation process with the rotor stored energy of the electrical machine, we recalculate $\omega_{2} *$ optimal values for the time diapason 5-10 seconds with a 1 second step and also $\omega_{2 *}$ optimal was recalculated using simple equations (2), (3) and (4). The results of accurate and simple methods are graphically presented in Fig. 5.

Taking into account $W_{\text {rot }}$, we can increase the minimal rotation speed and in this way to reduce electrical machine mass and increase flywheel mass (2), which provides EMB cost reduction. Using accurate design process relative rotor stored kinetic energy is calculated as a function of relative angular velocity at the end of the discharge process (Fig. 6.); for all calculations we were using constant amount of energy, which EMB can provide to the load, $W=0.65 \mathrm{kWh}$.

\section{MAGNETIZATION CURVES APPROXIMATION}

There are a lot of magnetization $B=f(H)$ curve approximation methods, the main goal of which is the equation for curves $H$ detection through value $B$ or contrary. The design of electrical machines requires recalculation of magnetic circuit for a huge number of times in the optimization iterative process [10]-[12]. If the designer wants to recalculate $k$ combinations of magnetic circuits, consisting of $n$ elements, it is clear, that magnetization curve approximation function or sub procedure is called for $k^{*} n$ times, if function execution time is $t$, it is clear how much time is needed to execute the general design program, only magnetic circuit calculation part. Some authors suggest to use hyperbolic sine function [5], others use $B(H)$ curves polynomial approximation [6] or partial polynomial approximation [7] close to the experimental point of function. Also it is necessary to examine basic variant, which is used in [8]; it is linear curve approximation; at the end each method is tested by entering random $B$ values, and calculation time is determined.

\section{A. Classic Linear Approximation Method}

The idea of this method is simple - at the beginning of the calculation we need only $B=f(H)$ curve table values, and for higher accuracy we should maximize the number of experimental curve points.

Approximation function analyzes the defined $B_{x}$ for which it is necessary to find $H_{x}$; internal counter detects how many $B$ 
table values are smaller than $B_{x}$, and result number $i$ goes to the approximation function output equation

$$
O U T_{\text {linear }}=H_{i}+\frac{\left(B_{x}-B_{i}\right)}{\left(B_{i+1}-B_{i}\right)}\left(H_{i+1}-H_{i}\right),
$$

where $H_{i}$ and $B_{i}$ are start points, $H_{i+1}$ and $B_{i+1}$ are end points of $H$ and $B$ diapasons; $B_{x}$ is magnetic flux density value required to find $H$. From the graph in Fig. 7 we can see, that when using wide step $[i, i+1]$ there is a large difference between real and linearly approximated curve, as a conclusion we should minimize the $B(H)$ intervals.

\section{B. Accelerated Linear Approximation}

The main disadvantage of classic linear approximation is $B_{x}$ analysis for $i$ detection, if $B_{x}$ is at the end of $B$ interval, we should make $i_{\max }-1$ step, where $i_{\max }$ is the number of $B(H)$ table strings. To reduce this part of approximation function we should divide interval $B$ into equal intervals. This modification allows determining $i$ by the equation

$$
i=\operatorname{Int}\left[\frac{B_{x}}{B_{\text {int }}}\right],
$$

where $I n t[]$ is programming environment function, the output of which returns the integer portion of a number in "[]", where $B_{\text {int }}$ is interval value, $B_{\text {int }}=\left|B_{i+1}-B_{i}\right|$. The output result of this method is equal to classical linear approximation.

\section{Polynomial Approximation}

Theoretically curve $B(H)$ can be defined by

$$
P_{n}(x)=\sum_{i=0}^{n} a_{i} x^{i},
$$

applying magnetization curve table. Each value of $H$, is a polynomial equation; as a result we have a system of linear equations with indefinite coefficients

$$
\left.\begin{array}{c}
a_{0}+a_{1} B_{0}+a_{2} B_{0}{ }^{2}+\ldots+a_{n} B_{0}{ }^{n}=H_{0} \\
a_{0}+a_{1} B_{1}+a_{2} B_{1}{ }^{2}+\ldots+a_{n} B_{1}{ }^{n}=H_{1} \\
\ldots \\
a_{0}+a_{1} B_{n}+a_{2} B_{n}{ }^{2}+\ldots+a_{n} B_{n}{ }^{n}=H_{n}
\end{array}\right\},
$$

where $a_{0}, \ldots a_{n}$ are unknown coefficients, $B_{0}, \ldots B_{n}$ is magnetic flux density and magnetic field strengths from $B(H)$ table. In matrix form (9) can be rewritten as

$$
[B][a]=[H] .
$$

Solution of (10) can be found using matrix method. As a result we know coefficients vector $[a]$, and can calculate $H_{x}$ for value $B_{x}$

$$
O U T_{\text {poly }}=a_{0}+a_{1} B_{x}+a_{2} B_{x}^{2}+\ldots+a_{n} B_{x}^{n} .
$$

\section{Partial Polynomial Approximation}

This type of magnetization curve approximation is similar to the simple polynomial and classic linear methods. In the first part of approximation process it is necessary to detect in which part of $B(H)$ curve $B_{x}$ is placed. When $i$ number is known, it is necessary to take the nearest $B(H)$ curve table value, and by using polynomial approximation to create the equation of approximation functions. This method has some advantages if to compare with the classical polynomial approximation. Fig. 8 presents polynomial approximation of Excel built trend line function; the main problem is that the polynomial of degree 6 has been used, as a result there exists a large difference between the approximation and real $B(H)$ curve. Fig. 9 gives partial polynomial approximation function result; the polynomial equation has 3 elements; the main disadvantage of this method is high accuracy only in the narrow interval near the value $B_{x}$.

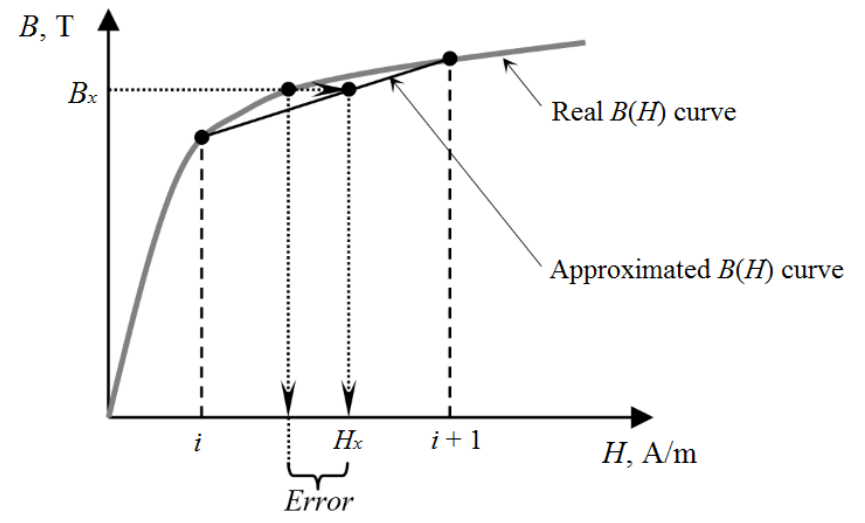

Fig. 7. $B(H)$ curve linear approximations.

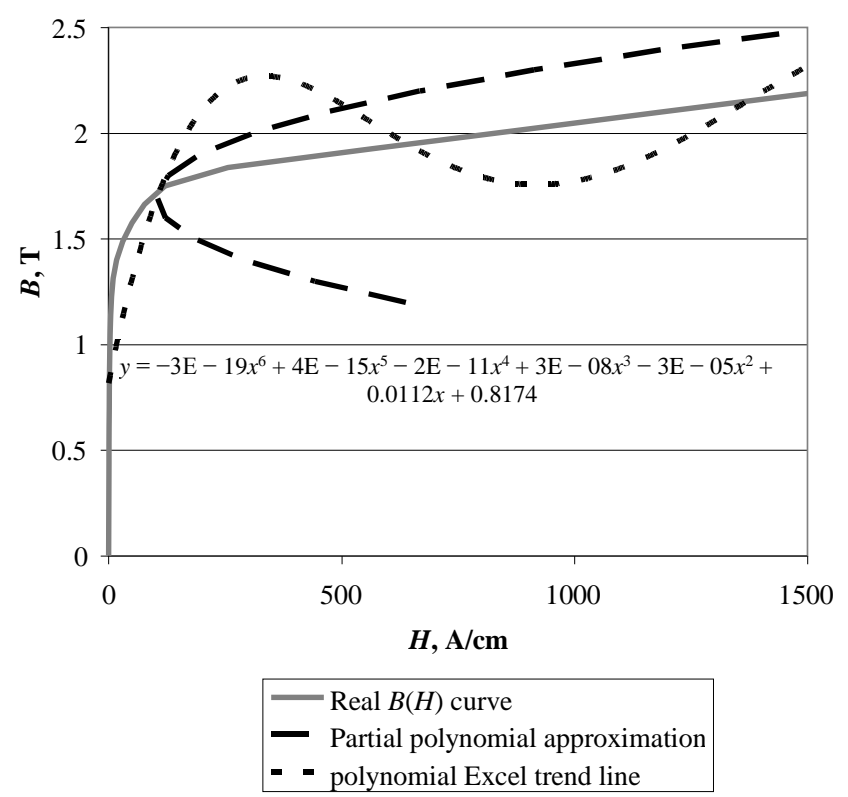

Fig. 8. Polynomial approximation of Excel.

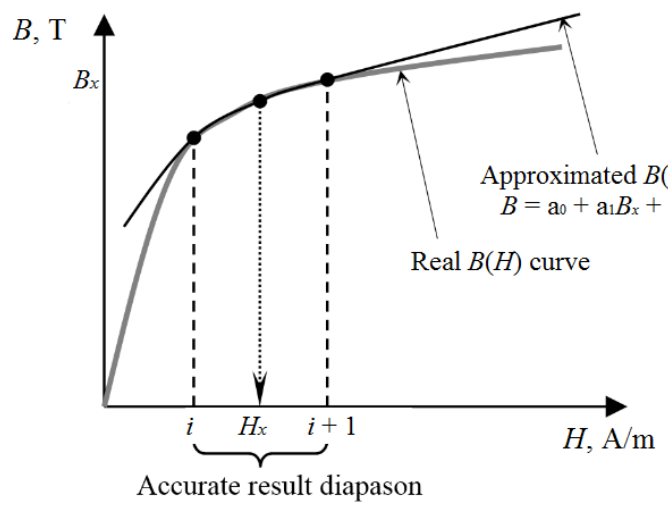

Fig. 9. Polynomial approximation with 3 elements. 


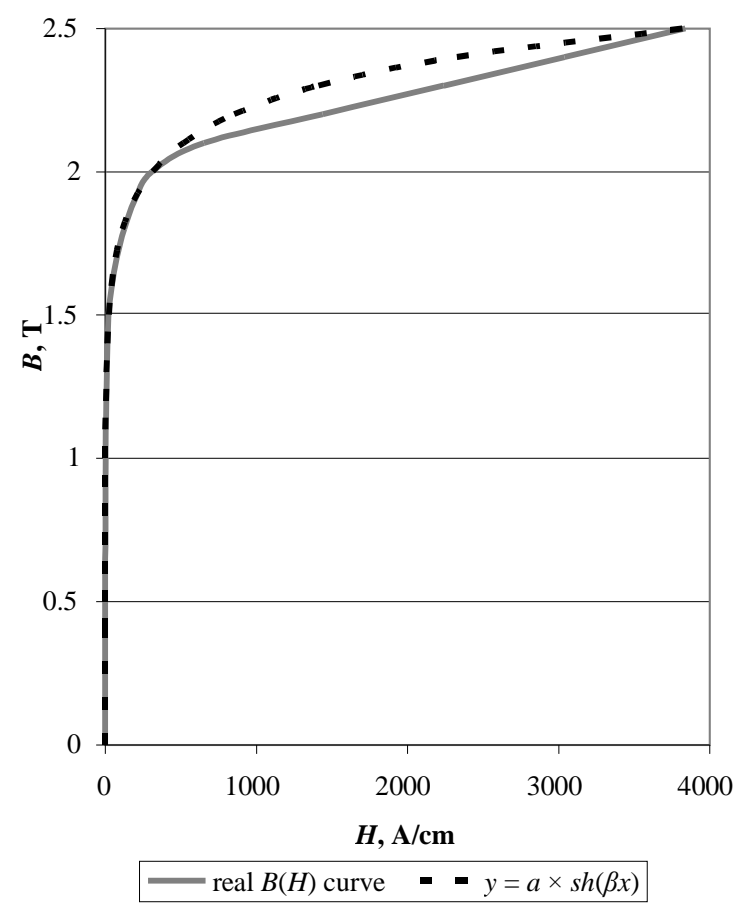

Fig. 10. Approximation with hyperbolic sine function.

TABLE I

APPROXIMATION TIMES FOR DIFFERENT METHODS

\begin{tabular}{|c|c|c|c|c|c|}
\hline $\begin{array}{c}\text { Testing } \\
\text { number }\end{array}$ & $\begin{array}{c}\text { Accelerated } \\
\text { linear, } \mathbf{s}\end{array}$ & Linear, s & $\begin{array}{c}\text { Polyno- } \\
\text { mial, s }\end{array}$ & $\begin{array}{c}\text { Hyperbo- } \\
\text { lic sinus, s } \mathbf{s}\end{array}$ & $\begin{array}{c}\text { Partial } \\
\text { polynomial, } \mathbf{s}\end{array}$ \\
\hline 3000 & 0 & 0 & 1.171875 & 0 & 0.171875 \\
\hline 10000 & 0.03125 & 0.046875 & 3.984375 & 0.015625 & 0.609375 \\
\hline 30000 & 0.125 & 0.140625 & 11.90625 & 0.03125 & 1.84375 \\
\hline 50000 & 0.21875 & 0.234375 & 19.65625 & 0.0625 & 3.0625 \\
\hline 100000 & 0.40635 & 0.46875 & 39.4375 & 0.125 & 6.078125 \\
\hline 300000 & 1.296875 & 1.421875 & 123.4375 & 0.359375 & 18.35938 \\
\hline 500000 & 2.09375 & 2.453125 & 208.625 & 0.59375 & 30.57813 \\
\hline
\end{tabular}

\section{E. Approximation with Hyperbolic Sine Function}

In [5] this method is given for nonlinear characteristics approximation in electric or magnetic circuits. Approximation curve equation is

$$
y=\alpha \times \operatorname{sh}(\beta x),
$$

where $\alpha, \beta$ are coefficients, $x$ is function argument. To find approximation function coefficients it is necessary to take two points from $y=f(x)$ curve; through these points a new curve is built. Taking $x$ and $y$ values we get the equation system with two unknown elements

$$
y_{1}=\alpha \times \operatorname{sh}\left(\beta x_{1}\right) \text { and } y_{2}=\alpha \times \operatorname{sh}\left(\beta x_{2}\right) .
$$

(13) can be solved making a new equation

$$
\begin{gathered}
y_{2} / y_{1}=\alpha \times \operatorname{sh}\left(\beta x_{2}\right) / \alpha \times \operatorname{sh}\left(\beta x_{1}\right) \text { or } \\
k=\operatorname{sh}\left(\beta x_{1}\right) / \operatorname{sh}\left(\beta x_{2}\right),
\end{gathered}
$$

where $k$ is a constant value, $k=y_{2} / y_{1}$. Using (14) coefficient $\beta$ can be found in iterative way and $\alpha$ is known from (13) from the first or the second equation. The advantage of this method is the simple coefficient calculation and fast execution, the main disadvantage is the choosing of two points, and the defining of optimal value of the coefficient (Fig. 10).

\section{DETECTION OF CALCULATION TIME OF APPROXIMATION METHOD}

For approximation functions described in Section IV a testing program was developed using standard random generator function when each function was tested. Execution time was detected by Excel standard function Timer(), which returns the number of seconds elapsed since midnight; this variable difference between the start and the end moment of program gives the necessary value.

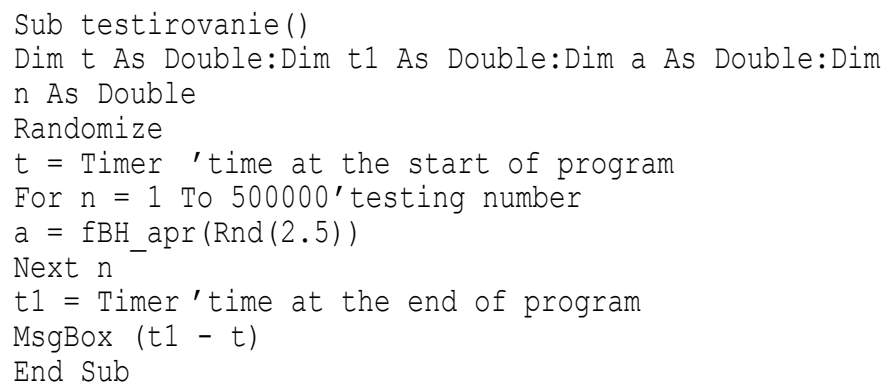

The results of these calculations are listed in Table I. From the table it is clear that the fastest function is the hyperbolic sine, but its disadvantage is that it is impossible to calculate the correct coefficient, but like in partial polynomial approximation in narrow diapason it can provide high enough accuracy. Good time results have both linear approximations, but their accuracy depends on number of values $B$ and $H$, hence the higher the accuracy the higher is the calculation time. Polynomial approximation depends on the number of elements; higher quantity of elements means higher execution time without guarantee of accuracy. As a conclusion the partial polynomial method has high accuracy of hyperbolic and linear approximation when using the polynomial method.

\section{ACCURACY LEVEL THROUGH THE APPROXIMATION METHODS}

Not only the execution time is the main goal, it is clear that the result should be accurate and as close as possible to $B=f(H)$ original curve shape. There are two possible groups of magnetic circuits.

For electrical apparatus the magnetic circuit usually is analyzed for the linear part of magnetization curve, in the part of nonlinear curve the accuracy problem is not so topical.

Going higher along the $B=f(H)$ we are in the magnetic circuit saturation zone, which is used only in calculation of electrical machines. The accuracy is very important because the approximation error can influence the result of the design. For analysis of accuracy we will take control points near the main nonlinearity of $B=f(H)$ curve. In Fig. 11 the error trend is displayed. 
Error of approximation

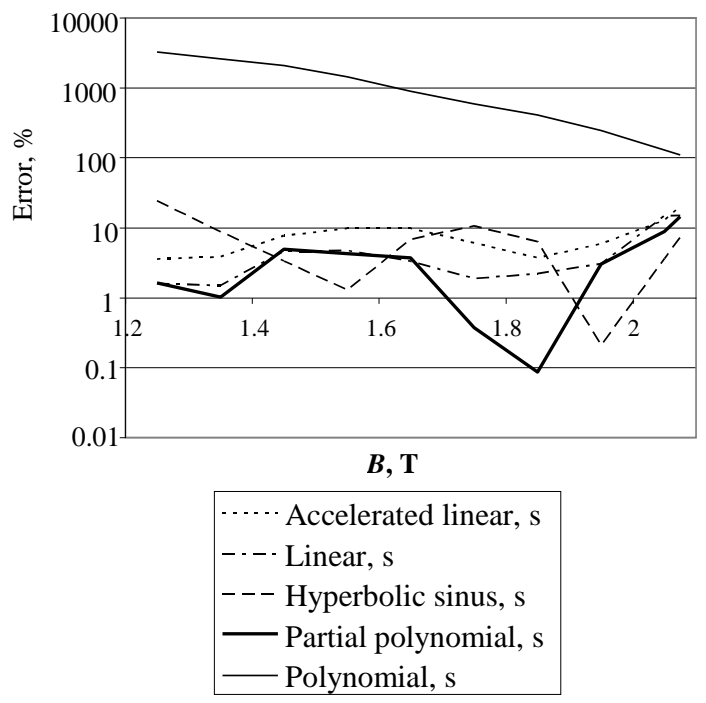

Fig. 11. Calculation error.

The error trends make it clear that only polynomial approximation method has very high calculation error; the other methods have equal error values. Polynomial approximation method has $n$ quantity of coefficients for each of member of polynomial equation; it gives good result only close to the points, which were used for its generation.

\section{CONCLUSION}

Kinetic energy stored in electrical machine rotor depends on discharge process power, process duration, and quantity of energy. The determination of $W_{\text {rot }}$ requires calculation of geometrical dimensions of the electrical machine going through accurate and standard design calculation process.

Taking into account the machine's rotor stored kinetic energy, we can increase the speed of minimal rotations and in this way reduce the mass of the electrical machine and increase flywheel mass which provides EMB cost reduction. Optimal calculation of $\omega_{2} *$ using accurate design process is higher than using simple calculation equations.

There are a lot of approximation methods of magnetization $B=f(H)$ curves, the main goal of which is equation for curve $H$ detection through value $B$ or on the contrary. The design of electrical machines requires recalculation of magnetic circuit for a huge number of times in the iterative process of optimization.

Faster execution methods for magnetization curve approximation such as partial polynomial method were analyzed in comparison with other methods. This method provides low calculation error too.

\section{REFERENCES}

[1] A. N. Ledovsky, I. I. Litvinov, M. E. Novikov and A. T. Timofeev, "Electric energy kinetic storage system development problem," Elektrichestvo, 1978, no. 3, pp. 41-45.

[2] D. A. But, B. L. Alievsy, S. R. Mizurin and P. V. Vasyukevich, Energy storages systems, Moscow: Energoatomizdat, 1991, p. 400.
[3] M. N. Anwar, I. Husain and A. V. Radun, "A Comprehensive Design Methodology for Switched Reluctance Machines," IEEE transactions on industry applications, vol. 37, no. 6, nov./dec. 2001, pp. 1687-1692. http://dx.doi.org/10.1109/28.968179

[4] O. D. Golberg, J. S. Gurin and I. S. Sviridenko, Proektirovanie električeskih mašin: Učebnik lja vtuzov, Moscow: Vishaja Škola, 1984, p. 431.

[5] L. A. Bessonov, Electrical Engineering fundamentals, Moscow: Vishaja shkola, 1996, p. 638.

[6] V. V. Nosach, An approximation exercises with personal computers, Moscow: MIKAP, 1994, p. 382. ISBN 5-85959-067-9

[7] A. Zviedris, Optimisation of electromagnetic system devices. Lectures, Riga: RTU, 2004, p. 46.

[8] A. Zviedris, Mathematical methods for personal computer. Lectures, Riga: RTU, 2004, p. 78.

[9] A. Podgornovs, A. Mesnajevs and A. Zviedris, "Determination Of Synchronous Machine's Characteristics Based On The Results Of The Mathematical Modelling Of The Magnetic Field," European Conference on Modelling and Simulation, 2011, Poland, ISBN: 978-0-9564944-2-9

[10] A. Podgornovs and A. Sipovičs, "Electromechanical Battery, Electrical Machines Mass Functions Analysis," RTU zinātniskie raksti. Energètika un elektrotehnika, 4. sēr., 29. sēj., 2011, 53.-57. lpp.

[11] S. Orlova, V. Pugačevs, M. Koṇuhova and N. Levins, "Non-Overlapping Concentrated Windings in Homopolar Inductor Machines," Int. Symp. on Power Electronics, Electrical Drives, Automation and Motion, SPEEDAM 2010: Conference Proceedings, Italy, Pisa, 14-16 June, 2010, pp. 282-286.

[12] M. Konuhova, K. Ketners, E. Ketnere and S. Zimina, "Investigations of the Undamped Field Effect to the Electromagnetic Processes in the Induction Machines," Energêttika un elektrotehnika, Latvia, Rīga, 14-16 Oct., 2009, pp. 47-50.

[13] A. Ruddell, "Investigation on Storage Technologies for Intermittent Renewable Energies: Evaluation and Recommended R\&D strategy," CCLRC Rutherford Appleton Laboratory, WP Report: Storage Technology ST6: Flywheel, Project funded by European Community under the 5th Framework Programme (1998-2002).

[14] H. Akagi and H. Sato, "Control and performance of a doubly-fed induction machine intended for a flywheel energy storage system," IEEE Transactions on Power Electronics, vol. 17, no. 1, ISSN 0885-8993

[15] J. Cibulka, "Kinetic Energy Recovery System by means of flywheel energy storage," Advanced Engineering, vol. 3, no. 1, 2009, ISSN 18465900 .

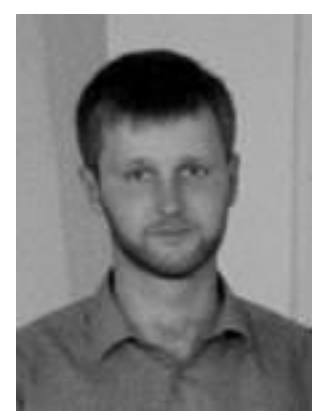

Andrejs Podgornovs received $B$. sc. ing. (2001), M. sc. ing. (2004) and Dr. sc. ing. (2009) degrees in electrical engineering from Riga Technical University, Riga, Latvia, Work experience: lecturer in Electrical Apparatuses and Machines, Lecturer in math methods of computer realization, Lecturer in Electrical machines magnetic field calculation, Riga Technical University, Riga. Research interests: synchronous motor self-excitation using third harmonic of a magnetic field, electrical machine field calculations using finite element method.

Contact information: phone:

+371 67089929, +371 29497539;

E-mail: andrejs.podgornovs@rtu.lv

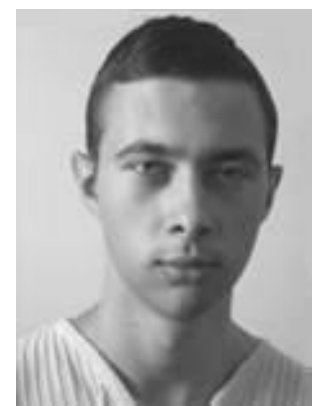

Antons Sipovichs received B. sc. ing. (2008) and $M$. sc. ing. (2010) degrees in electrical engineering from Riga Technical University, Riga, Latvia.

Research interests: electrical machine design and choice methods for kinetic energy storage in city electrical transport network, electrical machine automated design

Contact information: phone: +371 29623208;

E-mail: ant09ons@inbox.lv 